\title{
Avaliação hematológica e bioquímica de equinos suplementados com óleo de arroz semirrefinado, rico em gamaorizanol
}

\author{
[Hematological and biochemical evaluation of horses supplemented with semi-refined \\ rice oil enriched with gamma orizanol] \\ R.N. Oliveira ${ }^{1}$, A.P. Marques Jr..$^{2 *}$, P.R. Xavier $^{2}$, G.E.S. Alves ${ }^{2}$, P.R.O. Paes ${ }^{2}$, A.A.O. Gobesso ${ }^{3}$ \\ ${ }^{1}$ Aluno de graduação - Bolsista IC - EV-UFMG - Belo Horizonte, MG \\ ${ }^{2}$ Escola de Veterinária - UFMG \\ Av. Antônio Carlos, 6627 \\ 331270-901 - Belo Horizonte, MG \\ ${ }^{3}$ Faculdade de Medicina Veterinária e Zootecnia - USP - Pirassununga, SP
}

\begin{abstract}
RESUMO
Avaliou-se o efeito da suplementação com óleo de arroz sobre o peso e perfil hematológico de equinos submetidos a exercício físico moderado. Foram utilizados 14 equinos machos, com peso aproximado de $411 \mathrm{~kg}$, distribuídos entre o grupo tratado (GT; n=7), suplementado com óleo de arroz adicionado diariamente à dieta $(0,5 \mathrm{ml} / \mathrm{kg} / \mathrm{PV})$, e o grupo-controle $(\mathrm{GC} ; \mathrm{n}=7)$, tratado com óleo de soja $(0,5 \mathrm{ml} / \mathrm{kg} / \mathrm{PV})$. Foram feitas três avaliações: antes do início e aos 20 e 40 dias após o início do tratamento, as quais consistiram de determinação do peso, exame clínico e coleta de amostras de sangue dos animais, antes e após o exercício, para hematócrito, hemograma, dosagem de glicose, lactato e proteína total. Não houve diferença entre grupos e nem entre avaliações quanto às variáveis peso e proteína total. A glicose aumentou significativamente após o exercício na segunda coleta no GC e na terceira no GT. No GC, o lactato aumentou nas coletas após o exercício, enquanto no GT, os valores foram semelhantes antes e após. A suplementação com óleo de arroz na dieta foi determinante para impedir o aumento de lactato em equinos submetidos a exercício, o que pode ser relevante para aumentar o seu desempenho atlético.
\end{abstract}

Palavras-chave: equino, suplementação, óleo de arroz, lactato

\begin{abstract}
The effect of the supplementation with rice oil was evaluated on the weight and hematologic profile of equines submitted moderate physical exercise. Fourteen male equines, averaging $411 \mathrm{~kg}$, were distributed into treated group $(G T ; n=7)$, supplemented daily with rice oil added to the diet $(0.5 \mathrm{ml} / \mathrm{kg} / \mathrm{BW})$; and control group $(G C ; n=7)$, treated with soybean oil $(0.5 \mathrm{ml} / \mathrm{kg} / \mathrm{BW})$. Three evaluations were made before the treatment, and 20 and 40 days after the beginning of the treatment, consisting of the determination of the weight, the clinical examination, and the collection of blood samples before and after the exercise for hematocrit, hemogram, glucose, lactate, and total protein determinations. There was no difference between the groups, neither between evaluations for weight nor total protein. The glucose increased significantly after the exercise in the second collection in the GC and in the third in the GT. The GC lactate increased significantly in the collections after exercise; while in the GT, the results were similar before and after treatments. The supplementation of the diet with rice oil was determinant to hinder the lactate increase in the animals submitted to exercise, what could be relevant to increase their athletic performance.
\end{abstract}

Keywords: horse, supplementation, rice oil, lactate

Recebido em 29 de abril de 2009

Aceito em 30 de agosto de 2010

*Autor para correspondência (corresponding author)

E-mail: ampinho@ufmg.br 


\section{INTRODUÇÃO}

A quantidade de calorias que um equino necessita na dieta varia conforme a intensidade e o tipo de exercício a que é submetido, pois a contração muscular requer energia ingerida para obtenção, por via metabólica, de energia química, na forma de creatina-fosfato (CP) e adenosina-trifosfato (ATP) (Frape, 1994; Wilmore e Costill, 1994).

A energia requerida na dieta de equinos, comumente oferecida na forma de grãos, pode ser mais bem administrada via suplementação de óleo na dieta, uma vez que a ingesta rica em carboidratos, diferentemente de dieta rica em lipídios, pode ser causa de distúrbios digestivos e metabólicos (Marqueze et al., 2001), como rabdomiólise, fadiga muscular, cólica e laminite (Meyers et al., 1989; Frape, 1994; Dittrich et al., 2000). Cumprida tal exigência, obtém-se considerável aumento do desempenho físico do cavalo atleta (Harkins et al., 1992), podendo este ser observado no favorecimento da manutenção da velocidade de exercício por períodos maiores ou em velocidades maiores (Meyers et al., 1989).

Estudos mostraram que o metabolismo lipídico de cavalos pode ser aumentado quando estes são treinados e adaptados a dietas suplementadas com gordura, o que proporciona economia das reservas de glicogênio (Harkins et al., 1992; Frape, 1994; Dittrich et al., 2000), por inibir captação de glicose, glicogenólise, glicólise e oxidação de piruvato (Ferrante et al., 1994). Durante o exercício, o organismo libera adrenalina, a qual leva o tecido adiposo e o fígado a mobilizarem ácidos graxos fornecidos na suplementação com óleo (Valberg, 1996; Dittrich et al., 2000).

Hambleton et al. (1980), Harkins et al. (1992) e Valberg (1996) verificaram que a suplementação de lipídios em até $20 \%$ na dieta de equinos tem função ergogênica, ou seja, possibilita aumento da capacidade para o exercício, inversamente proporcional à elevação de lactato sanguíneo. Frape (1994) encontrou menor concentração de lactato sérico em animais que receberam acréscimo de lipídios na dieta, quando comparados aos não suplementados, independentemente de estarem em repouso ou em trabalho. Sugeriram que a suplementação com lipídios diminui a concentração de lactato e, consequentemente, reduz a incidência de fadiga muscular, que pode ser também causada por hipoglicemia, esgotamento de glicogênio muscular, acúmulo de $\mathrm{NH}_{3}$ na célula, perda de adenosina trifosfato (ATP) muscular e eletrólitos (Hiney e Potter, 1996). Ademais, já se verificou que o lactato em alta concentração estimula nociceptores e intensifica a propagação de impulsos algogênicos pelas vias aferentes até a córtex cerebral, de forma a exceder o limiar de dor (Smith, 1996).

Este trabalho teve o objetivo de avaliar o efeito da suplementação com óleo de arroz (Gama Horse ${ }^{\circledR)}$ ) sobre: peso, proteína total, hematócrito, glicose e lactato sanguíneos antes e após exercício físico moderado de equinos.

\section{MATERIAL E MÉTODOS}

O experimento foi realizado com 14 equinos machos, com idade entre três e 14 anos, distribuídos em dois grupos de sete animais: grupo-controle (GC) e grupo tratado (GT). Os do GC foram suplementados com óleo de soja em volume igual ao óleo de arroz (Gama Horse ${ }^{\circledR}$ ) oferecido aos animais do GT. Antes do início do experimento, os equinos receberam ivermectina $(200 \mu \mathrm{g} / \mathrm{kg} / \mathrm{via}$ oral) e foram avaliados antes e após a realização de exercícios moderados. Projeto aprovado pelo Comitê de Ética em Experimentação Animal (CETEA-UFMG), protocolo $003 / 08$

Na primeira avaliação, a do tempo basal, foram realizados os primeiros exames, seguida do início da suplementação com o óleo de arroz. Após 20 dias de tratamento, fez-se a segunda avaliação, e após mais 20 dias, a terceira e última. Foram colhidas amostras de sangue da jugular nos animais em repouso e após o exercício. Os exames realizados foram avaliações do peso e de rotina clínica, do hemograma, das proteínas totais, da glicemia e da lactacidemia.

O tratamento consistiu na adição diária de óleo de arroz na dieta no volume de $0,5 \mathrm{ml} / \mathrm{kg}$ de peso vivo, por um período de 40 dias. Todos os animais receberam na dieta total $20 \mathrm{mCal}$ de energia digestível (ED) e 800 gramas de proteína bruta (PB)/dia para $400 \mathrm{~kg}$ de peso vivo, sendo $10 \mathrm{mCal}$ da ED e $455 \mathrm{~g}$ de $\mathrm{PB} /$ dia para $400 \mathrm{~kg}$ de peso. Nesse caso, $10 \mathrm{mCal}$ da ED e 
445g da PB originaram-se do concentrado, e $10 \mathrm{mCal}$ da $\mathrm{ED}$ e $345 \mathrm{~g}$ de $\mathrm{PB}$ da forragem, obedecida a proporção de $40 \mathrm{~g}$ de $\mathrm{PB} / \mathrm{mCal}$, de forma que um animal de $400 \mathrm{~kg}$ de peso recebesse $3,5 \mathrm{~kg}$ de ração com $13 \%$ de $\mathrm{PB}$ e $2,8 \mathrm{mCal} / \mathrm{kg}$. As análises estatísticas constituíram-se de análise de variância e teste SNK $(\mathrm{P}<0,05)$ para comparação de médias.

\section{RESULTADOS E DISCUSSÃO}

Não houve diferença $(\mathrm{P}>0,05)$ entre os grupos (Tab. 1) nem na comparação entre coletas quanto ao peso, antes e após o exercício, portanto não se observou efeito mensurável do uso do óleo de arroz Gama Horse ${ }^{\circledR}$ (Tab. 1).

Tabela 1. Peso (kg) de equinos suplementados com óleo de soja (grupo-controle - GC) ou com óleo de arroz semirrefinado rico em gamaorizanol (grupo tratado - GT)

\begin{tabular}{lll}
\hline Coleta & GC & GT \\
\hline Primeira $^{1}$ & 394 & 429,86 \\
Segunda $^{2}$ & 386,43 & 407,86 \\
Terceira $^{2}$ & 401 & 411,43 \\
\hline
\end{tabular}

1: antes da suplementação; 2: após a suplementação. Não houve diferença entre tratamentos (teste SNK, P>0,05).

Segundo Lehninger et al. (2006), a maior parte de ácidos graxos ingeridos seguem duas vias, conforme a necessidade orgânica: são incorporados em triacilgliceróis e armazenados em energia metabólica, ou são integrados em fosfolipídios componentes de membranas. Um animal em fase de crescimento rápido necessita da síntese de fosfolipídios para síntese de novas membranas, diferente de um animal que já completou seu desenvolvimento, como os usados neste experimento, cuja maior parte de ácidos graxos é destinada a gorduras de reserva (Lehninger et al., 2006). Portanto, conseguir o aumento da condição corporal desses equinos e, consequentemente, a total manifestação do desempenho deles (Hintz, 1994), via suplementação de óleo de arroz na dieta, só será possível se a oferta de triacilgliceróis na dieta for superior às suas necessidades catabólicas. Para obter ganho de peso significativo desses animais, seria necessário fornecer a eles maior quantidade desse suplemento, ou, então, suplementá-los por um período mais prolongado.

Não houve diferença $(\mathrm{P}>0,05)$ entre os grupos e nem entre as avaliações quanto à variável proteína total (Tab. 2) nem antes e nem após o exercício.

Tabela 2. Concentração de proteína total (g/dL) em equinos suplementados com óleo de soja (grupocontrole - GC) ou com óleo de arroz semirrefinado, rico em gamaorizanol (grupo tratado - GT), antes e depois do exercício

\begin{tabular}{lllll}
\hline Coleta & GC antes & GC após & GT antes & GT após \\
\hline Primeira $^{1}$ & 9,23 & 10,43 & 9,43 & 10,65 \\
Segunda $^{2}$ & 7,34 & 7,57 & 7,40 & 8,00 \\
Terceira $^{2}$ & 6,96 & 7,20 & 7,20 & 7,50 \\
\hline
\end{tabular}

1: antes da suplementação; 2: após a suplementação. Não houve diferença entre os tratamentos (teste SNK, P>0,05).

As primeiras fontes de energia utilizadas pelo organismo equino são os carboidratos, seguidos pelos lipídios e pelas proteínas, preferencialmente nessa sequência, devido às diferenças de eficiência no oferecimento de energia (Hintz, 1994). Entretanto, no NRC (Nutrients ..., 1989), consta que dietas com concentrações de proteínas acima de $11 \%$ influenciam diretamente no desempenho do cavalo atleta, possivelmente porque alterações na concentração de proteína total plasmática e no hematócrito resultam comumente em alterações no volume plasmático (Smith, 1996). Exercícios podem resultar em hipertrofia muscular e aumento da degradação proteica, particularmente quando a energia é insuficiente (Hintz, 1994), o que não ocorreu nos animais desse experimento, que receberam dietas suplementadas com óleo de arroz.

Na segunda e terceira coletas, somente após o exercício os animais apresentaram taxas de hematócrito mais elevadas, o que indica oscilação do equilíbrio hídrico e ausência de influência da suplementação com óleo (Tab. 3). O aumento nos valores de hematócrito é 
esperado após o exercício, pois o volume globular é diretamente proporcional à intensidade do esforço físico. Smith (1996) ressaltou que, na espécie eqüina, há amplitude alta na faixa de normalidade de hematócrito, pois cavalos podem facilmente mobilizar eritrócitos esplênicos, como ocorre, por exemplo, nos casos de excitação, dor ou liberação de catecolaminas, tornando difícil a obtenção real de valores dessa variável com o animal em repouso.

Tabela 3. Hematócrito (\%) de equinos suplementados com óleo de soja (grupo-controle - GC) e com óleo de arroz semirrefinado, rico em gamaorizanol (grupo tratado - GT), antes e após o exercício

\begin{tabular}{lllll}
\hline Coleta & GC antes & GC após & GT antes & GT após \\
\hline Primeira $^{1}$ & $38,29 \mathrm{a}$ & $41,71 \mathrm{a}$ & $37,29 \mathrm{a}$ & $44,50 \mathrm{a}$ \\
Segunda $^{2}$ & $37,57 \mathrm{~b}$ & $43,29 \mathrm{ab}$ & $36,86 \mathrm{~b}$ & $48,14 \mathrm{a}$ \\
Terceira $^{2}$ & $35,14 \mathrm{~b}$ & $41,17 \mathrm{a}$ & $35,43 \mathrm{~b}$ & $43,83 \mathrm{a}$ \\
\hline
\end{tabular}

1: antes da suplementação; 2: após a suplementação. Médias seguidas por letras distintas na mesma linha diferem entre si pelo teste $\mathrm{SNK}(\mathrm{P}>0,05)$.

Houve aumento significativo $(\mathrm{P}<0,05)$ de glicose na segunda coleta no GC após o exercício e na terceira coleta no GT após o exercício, o que permitiu deduzir que o óleo de arroz não foi o diferencial quanto à glicose, pois houve aumento de sua taxa também no GC (Tab. 4). Entretanto, comprova-se a proposição de Hambleton et al. (1980), que relataram proporção direta entre suplementação lipídica e glicemia, e de outros pesquisadores (Meyer et al., 1989; Harkins et al., 1992; Ferrante et al., 1994; Dittrich et al., 2000), que citaram aumento de glicogênio em animais com dieta suplementada de lipídios devido à inibição da captação de glicose, glicogenólise, glicólise e oxidação de piruvato.

Tabela 4. Concentração de glicose $(\mathrm{mg} / \mathrm{dL})$ em equinos suplementados com óleo de soja (grupo-controle GC) e com óleo de arroz semirrefinado, rico em gamaorizanol (grupo tratado - GT), antes e depois do exercício

\begin{tabular}{lllll}
\hline Coleta & GC antes & GC após & GT antes & GT após \\
\hline Primeira $^{1}$ & $102,14 \mathrm{a}$ & $133,00 \mathrm{a}$ & $101,29 \mathrm{a}$ & $146,17 \mathrm{a}$ \\
Segunda $^{2}$ & $93,86 \mathrm{~b}$ & $131,14 \mathrm{a}$ & $105,86 \mathrm{ab}$ & $183,43 \mathrm{a}$ \\
Terceira $^{2}$ & $112,86 \mathrm{ab}$ & $134,33 \mathrm{a}$ & $91 \mathrm{~b}$ & $143,33 \mathrm{a}$ \\
\hline
\end{tabular}

1: antes da suplementação; 2: após a suplementação.

Médias seguidas por letras distintas na mesma linha diferem entre si pelo teste SNK $(\mathrm{P}>0,05)$.

Quanto ao lactato, em todas as três coletas houve aumento somente no GC após o exercício, enquanto no GT as médias foram semelhantes, antes e após o exercício (Tab. 5). A suplementação com óleo de arroz parece ter sido determinante para não haver aumento significativo de lactato nos animais pósexercício. Os resultados de lactato assemelhamse aos de Meyer et al. (1989) e Mattos et al. (2006), cujos animais alimentados com dietas contendo óleo apresentaram menores valores de lactato.

Tabela 5. Concentração de lactato $(\mathrm{mg} / \mathrm{dL})$ de equinos suplementados com óleo de soja (grupo-controle GC) e com óleo de arroz semirrefinado, rico em gamaorizanol (grupo tratado - GT), antes e depois do exercício

\begin{tabular}{lllll}
\hline Coleta & GC antes & GC após & GT antes & GT após \\
\hline Primeira $^{1}$ & $1,96 \mathrm{~b}$ & $3,03 \mathrm{a}$ & $1,69 \mathrm{~b}$ & $2,28 \mathrm{ab}$ \\
Segunda $^{2}$ & $2,14 \mathrm{~b}$ & $3,73 \mathrm{a}$ & $2,07 \mathrm{ab}$ & $3,07 \mathrm{ab}$ \\
Terceira $^{2}$ & $1,91 \mathrm{~b}$ & $3,12 \mathrm{a}$ & $1,83 \mathrm{~b}$ & $2,43 \mathrm{~b}$ \\
\hline
\end{tabular}

1: antes da suplementação; 2: após a suplementação.

Médias seguidas por letras distintas na mesma linha diferem entre si pelo teste $\mathrm{SNK}(\mathrm{P}>0,05)$. 


\section{CONCLUSÃO}

A suplementação com óleo de arroz rico $\mathrm{em}$ gamaorizanol na dieta de equinos foi determinante para impedir o aumento significativo de lactato em equinos submetidos a exercício.

\section{REFERÊNCIAS BIBLIOGRÁFICAS}

DITTRICH, R.L.; DITTRICH, J.R.; FLENUNG, J.S. et al. Valores bioquímicos séricos em potros da raça puro sangue inglês suplementados com diferentes tipos de gordura. Cienc. Rural, v.30, p.631-634, 2000.

FERRANTE, P.L.; TAYLOR, L.E.; KRONFELD, D.S. et al. Blood lactate concentration during exercise in horse fed a high-fat diet an administered sodium bicarbonate. J. Nutr., v.124, p.2738-2739, 1994.

FRAPE, D.L. Diet and exercise performance in the horse. Proc. Nutr. Soc., v.53, p.189-206, 1994.

HAMBLETON, P.L.; SLADE, L.M.; HAMAR, D.W., et al Dietary fat and exercise conditioning effect on metabolic parameters in the horse. $J$. Anim. Sci., v.51, p.1330-1339, 1980.

HARKINS, J.D.; MORRIS, G.S.; TULBY, R.T. et al. Effect of added fat on racing performance in thoroughbred horse. J. Equine Vet. Sci., v.12, p.123-129, 1992.

HINEY, K.M.; POTTER, G.D. A review of recent research on nutrition and metabolism in the athletic horse. Nutr. Res. Rev., v.9, p.149173, 1996.
HINTZ, H.F. Nutrition and equine performance. J. Nutr., v.124, p.2723-2729, 1994.

LEHNINGER, A.L.; NELSON, D.L.; COX, M.M. Princípios de Bioquímica. 4.ed. São Paulo: Sarvier, 2006. 1202p.

MARQUEZE, A.; KESSLER, A.M.; BERNARDI, M.L. Aumento do nível de óleo em dietas isoenergéticas para cavalos submetidos a exercício. Cienc. Rural, v.31, p.491-496, 2001.

MATTOS, F.; ARAÚJO, K.V.; LEITE, G.G. et al. Uso de óleo na dieta de equinos submetidos ao exercício. Rev. Bras. Zootec., v.35, p.13731380, 2006.

MEYERS, M.C.; POTTER, G.D.; EVANS, J.W. et al. Physiologic and metabolic response of exercising horses to added dietary fat. J. Equine Vet. Sci., v.9, p.218-223, 1989.

NUTRIENT requirements of horses. 5.ed. Washington: National Academy, 1989. 100p.

SMITH, B.P. (Ed). Large animal internal medicine: diseases of horses, cattle, sheep, and goats. 2.ed. St. Louis: Mosby - Year Book, 1996. 2040p.

VALBERG, S.J. Muscular causes of exercise intolerance in horses. Vet. Clin. N. Am.: Equine Pract., v.12, p.495-515, 1996.

WILMORE, J.H.; COSTILL, D.L. Basic energy systems. In: WILMORE, J.H.; COSTILL, D.L. (Eds). Physiology of sport and exercise. Champaign: Human Kinetics, 1994. p.92-121. 